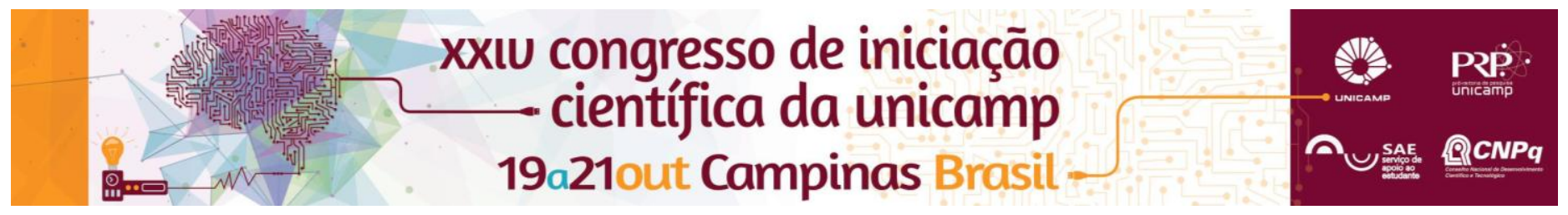

\title{
OBTENÇÃO E CARACTERIZAÇÃO DE ORGANOGÉIS DE ÓLEO DE SOJA ESTRUTURADO COM MONOESTEARATO DE SORBITANA E MONOGLICERÍDIOS
}

\author{
Ana K. S. de Souza*, Karina M. Barbosa, Daniel Barrera-Arellano.
}

\section{Resumo}

Os organogéis são uma alternativa nutricionalmente atrativa ao uso de gorduras convencionais, que normalmente apresentam alto teor de ácidos graxos saturados. O presente estudo teve como objetivo formular organogéis de óleo de soja estruturados com uma combinação de Monoestearato de Sorbitana (SMS) e Monoglicerídios (MAG). Determinações de consistência (compressão/extrusão) e microestrutura mostraram que a estruturação dos MAG é muito superior a do SMS, atuando este último como desestruturante dos organogéis de óleo de soja.

\section{Palavras-chave \\ Organogel, monoestearato de sorbitana, monoglicerídios.}

\section{Introdução}

Organogéis são materiais viscoelásticos sólidos ou semissólidos, formado por uma parte líquida apolar e um ou mais agentes estruturantes ${ }^{[1]}$.

Os organogéis possuem a atrativa particularidade de atribuir características a um produto tais como textura e consistência semelhante a uma gordura convencional, contudo isento de ácidos graxos trans e redução significativa no conteúdo de saturados ${ }^{[2]}$. O objetivo deste trabalho foi preparar organogéis de óleo de soja com monoestearato de sorbitana (SMS) e monoglicerídios (MAG), obtendo-se assim um sistema binário, com concentração total fixa de $8 \%(\mathrm{~m} / \mathrm{m})$. Os organogéis obtidos foram caracterizados física e estruturalmente.

\section{Resultados e Discussão}

A análise de consistência foi realizada a $25^{\circ} \mathrm{C}$ utilizandose o texturômetro TA-XT2i (Stable Micro Systems, Inglaterra), controlado por microcomputador e probe cilíndrica de $35 \mathrm{~mm}$ de comprimento e $25 \mathrm{~mm}$ de diâmetro.

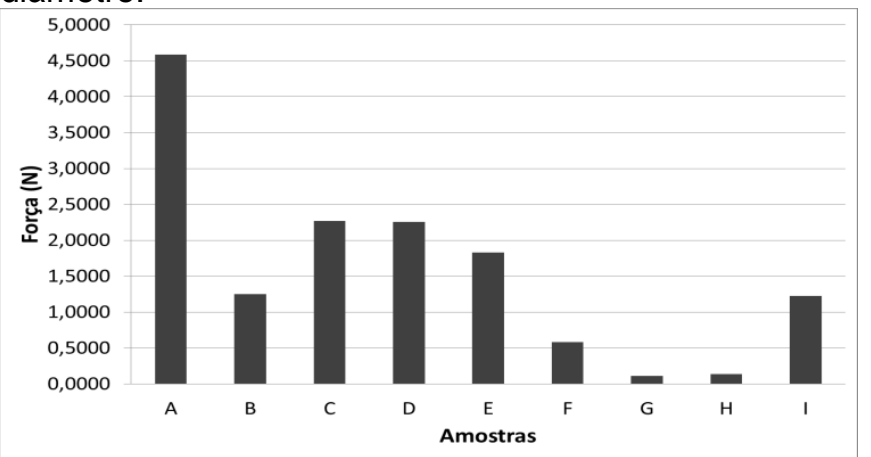

Figura 1. Dureza máxima em organogéis de óleo de soja estruturados com SMS e MAG.

Observa-se que, com a inclusão do SMS na formulação, a rede torna-se menos rígida, de forma que as amostras apresentam menor resistência à compressão (Figura 1).

A análise da microestrutura dos organogéis foi realizada por microscopia de luz polarizada (MLP) comum em microscópio Olympus BX-51 (Olympus, Japão) a $25^{\circ} \mathrm{C}$.

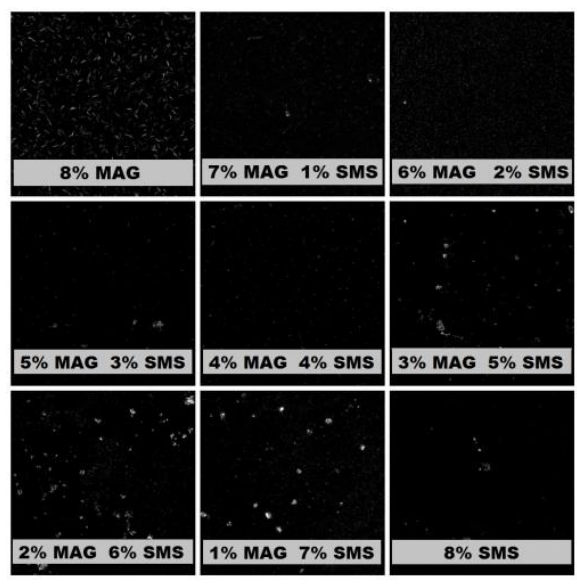

Figura 2. Microfotografias de organogéis de óleo de soja estruturados com SMS e MAG, obtidas por microscópio de luz polarizada (100X).

Observa-se que conforme o teor de MAG é aumentado, mais homogênea torna-se a rede, composta por cristais finos (Figura 2), em formato de agulha. O SMS forma cristais em forma de feixes fibrilares espalhados radialmente, os quais tendem a se aglomerar, formando uma rede mais heterogênea (Figura 2), levando à instabilidade observada na análise de consistência.

\section{Conclusões}

O MAG promoveu a formação de uma rede homogênea e estável para a obtenção de organogéis de óleo de soja, enquanto que o SMS não apresentou capacidade estruturante em concentrações de até $8 \%(\mathrm{~m} / \mathrm{m})$ nas mesmas condições. Quando utilizado em conjunto com o MAG, o SMS atua como redutor da consistência dos organogéis.

\section{Agradecimentos}

Ao Laboratório de Óleos e Gorduras (FEA) da Unicamp, aos integrantes que o compõem e ao Conselho Nacional de Desenvolvimento Científico e Tecnológico (CNPq).

${ }^{1}$ DASSANAYAKE, L. S. K.; KODALI, D. R.; UENO, S.; SATO, K. Physical Properties of Rice Bran Wax in Bulk and Organogels. Journal of the American Oil Chemists' Society, v. 86, n. 12, p. 1163-1173. 2009.

${ }^{2}$ DASSANAYAKE, L. S. K., KODALI, D. R., UENO, S. Formation of oleogels based on edible lipid materials. Current Opinion in Colloid \& Interface Science v. 16, p. 432-439. 2011. 